\title{
Geographical variations of prothrombotic polymorphisms: An important emerging risk factor for ischemic stroke
}

\author{
Maria Thomas, Jeyaraj D. Pandian ${ }^{1}$ \\ Departments of Biochemistry and ${ }^{1}$ Neurology, Christian Medical College, Ludhiana, Punjab-141 008, India
}

\author{
Address for correspondence: \\ Dr. Jeyaraj D. Pandian, \\ Department of Neurology, \\ Head of Research, Betty Cowan \\ Research and Innovation Center, \\ Christian Medical College, Ludhiana, \\ Punjab - 141 008, India. \\ E-mail: jeyarajpandian@hotmail. \\ com
}

PMID: 19934548

DOI: $10.4103 / 0028-3886.57787$

Ischemic stroke is a heterogeneous multifactorial disease that is affected by several genetic mutations and environmental factors. Various polymorphisms and mutations have been described as risk factors for stroke and they include angiotensin-converting enzyme (ACE) genotype, factor $\mathrm{V}$ Leiden, prothrombin G20210A, methylene tetrahydrofolate reductase (MTHFR), human platelet antigen type 1, factor XIII, apolipoprotein $\mathrm{E}$ (apo E), plasminogen activator inhibitor-14G/5G genotypes, phosphodiesterase $4 \mathrm{D}$ and 5-lipooxygenase-activating protein. ${ }^{[1,2]}$

Homocysteine (Hcy) is a variant of the amino acid cysteine, differing only by having an additional methylene (-CH2-) group. The conversion of Hcy into methionine is dependent on the enzyme MTHFR. ${ }^{[2]}$ This enzyme has multiple known polymorphisms of the gene coding for it. This nucleotide polymorphism is important since it results in variability in the activity of the enzyme and hence variability in the levels of Hcy. ${ }^{[3]}$ Over past two decades MTHFR C677T polymorphisms have been widely studied and has been identified as an independent risk factor for ischemic stroke by some ${ }^{[4,5]}$ but not by others ${ }^{[6,7]}$ and is associated with an increase in plasma Hcy, an important proatherogenic risk factor causing endothelial dysfunction and vascular injury by a variety of mechanisms. ${ }^{[8,9]}$ In this issue Al-Allawi et al., ${ }^{[10]}$ and Sun et al., ${ }^{[11]}$ describe two interesting studies regarding MTHFR polymorphism and its association with ischemic stroke. In the hospital-based study from Iraq, patients with MTHFR C677T, TT genotype had 4.85 times higher risk of developing ischemic stroke than the CC genotype. Serum Hcy was elevated significantly among the patients and also in those with both TT and CT genotypes compared with those with CC genotype. ${ }^{[10]}$ In the second paper, researchers from China $^{[11]}$ studied MTHFR polymorphism in ischemic stroke patients with type 2 diabetes. Plasma Hcy was elevated in diabetic patients with TT genotype, and C677T mutation of MTFHR gene was independently associated with ischemic stroke in type 2 diabetes. However, in another report from Italy, Salvatore et al., ${ }^{[12]}$ did not find any difference in the prevalence of prothrombotic polymorphisms in patients with cryptogenic and non-cryptogenic strokes. Among the Asians, the frequency of MTHFR polymorphism is $11 \%$ in the Japanese and $12.3 \%$ in the Chinese populations. ${ }^{[13]}$ Indians too show marked variability in the carrier frequency for this polymorphism. In a study from Mumbai on patients with venous thromboembolism, CT and TT genotypes were present in 14.9 and $1.2 \%$ of patients, respectively. ${ }^{[14]}$ In a recent report from India the MTHFR $677 \mathrm{C}>\mathrm{T}$ polymorphism showed association with both elevated Hcy levels as well as stroke. ${ }^{[15]}$ 
Apolipoprotein B (Apo B) plays an important role in lipoprotein metabolism, and increased plasma levels of this lipoprotein have been identified as a predictor of increased risk of cardiovascular disease and ischemic stroke. ${ }^{[16]}$ In this issue, Zhang et al., ${ }^{[17]}$ has reported the association of Apo B polymorphism C7673T in patients with ischemic stroke with and without family history. The $\mathrm{T}$ alleles frequency of the C7673T polymorphism was significantly higher in both ischemic stroke patients with and without family history when compared with the control group. The serum levels of total cholesterol (TC) and low density lipoprotein (LDL) cholesterol were significantly high in the TT and TC genotypes than that in the CC genotype. Genetic variants have been reported in the Apo B gene of which the most widely studied is the Xba 1 polymorphism in exon 26 (C7673T). ${ }^{[18]}$ The physiological role of this polymorphism is still unclear but has been shown to be associated with elevated basal plasma total and LDL cholesterol concentrations. ${ }^{[18]}$

All the four papers on prothrombotic polymorphisms in stroke published in this issue are limited by small sample size and hospital-based cohort. The reports on MTHFR polymorphisms and ischemic stroke did not estimate the folic acid and Vitamin B12 levels, which would influence the Hcy level. Genetic etiology of stroke involves the influence of several genetic loci modulating different pathophysiological processes. Association studies of various single nucleotide polymorphisms with ischemic stroke have yielded variable results. Hence it is important to undertake population-based case-control studies to identify genetic markers and their association with clinical risk factors. This may in future permit early identification of population at risk for development of ischemic stroke, which in turn may help in more effective prevention.

\section{References}

1. Hankey GJ. Potential new risk factors for ischemic stroke what is their potential? Stroke 2006;37:2181-8.

2. Solenski NJ. Emerging risk factors for cerebrovascular disease. Curr Drug Targ 2007;8:802-16.

3. Casas JP, Bautista LE, Smeeth L, Sharma P, Hingorani AD. Homocysteine and stroke: Evidence on a causal link from Mendelian randomization. Lancet 2005;365:224-32.
4. Margaglione M, D'Andrea G, Giuliani N, Brancaccio V, Domenico De Lucia, Grandone E, et al. Inherited prothrombotic conditions and premature ischemic stroke: Sex difference in the association with factor V Leiden. Arterioscler Thromb Vase Biol 1999;19:1751-6.

5. Soriente L, Coppola A, Madonna P. Homozygous C677T mutation of the 5,10 methylenetetrahydrofolate Reductase gene and hyperomocysteinemia in Italian patients with a history of early-onset ischemic stroke. Stroke 1998;29:869-71.

6. Lopaciuk S, Bykowska K, Kwiecinski H, Mickielewicz A, Czlcankawska A, Mendel T, et al. Factor V Leiden, prothrombin gene G20210A variant, and methylenetetrahydrofolate reductase C677T genotype in young adults with ischemic stroke. Clin Appl Thromb 2001;7:346-50.

7. Grossmann R, Geisen U, Merati G, Müllges W, Schambeck CM, Walter U, et al. Genetic risk factors in young adults with 'cryptogenic' ischemic cerebrovascular disease. Blood Coagul Fibrinolysis 2002;13:583-90.

8. Jacobsen DW, Catanescu O, Dibello PM, Barbato JC. Molecular targeting by homocysteine: A mechanism for vascular pathogenesis. Clin Chem Lab Med 2005;43:1076-83.

9. Splaver A, Lamas GA, Hennekens CH. Homocysteine and cardiovascular disease: Biological mechanisms, observational epidemiology, and the need for randomized trials. Am Heart J 2004;148:34-40.

10. Al-Allawi NAS, Avo AS, Jubrael JM. Methylenetetrahydrofolate reductase $\mathrm{C} 677 \mathrm{~T}$ polymorphism in Iraqi patients with ischemic stroke. Neurol India 2009; $57: 631-5$

11. Sun JZ,Xu Y, Lu H, Zhu Y. Polymorphism of the methylenetetrahydrofolate reductase gene association with homocysteine and ischemic stroke in type 2 diabetes. Neurol India 2009;57:589-93

12. Salvatore CR, Paolino LS, Salvatore S, Angelina L, Paolo P, Rodolfo S, et al. Prevalence of prothrombotic polymorphisms in a selected cohort of cryptogenic and noncryptogenic ischemic stroke patients. Neurol India 2009;57:636-7

13. Cronin S, Furie KL, Peter J. Kelly PJ. Dose-Related Association of MTHFR 677T Allele With Risk of Ischemic Stroke Evidence From a Cumulative Meta-Analysis. Stroke 2005;36;1581-87.

14. Ghosh K, Shetty S, Madkaiker M, Pawar A, Nair S, Khare A, et al. Venous thromboembolism in young patients from western India: A study. Clin Appl Thromb Hemost 2001;7:158-65.

15. Biswas A, Ranjan R, Meena A, Akhter MS, Yadav BK, Munisamy M, et al. Homocystine levels, polymorphisms and the risk of ischemic stroke in young Asian Indians. J Stroke Cerebrovase Dis 2009;18:103-10.

16. Walldius G, Aastveit AH, Jungner I. Stroke mortality and the apoB/ apoA-I ratio: Results of the AMORIS prospective study. J Intern Med 2006;259:259-66.

17. Zhang L, Zeng Y, Ma M, Yang Q, Hu Z, Du X. Association study between C7673T polymorphism in Apolipoprotein B gene and cerebral infarction with family history in a Chinese population. Neurol India $2009 ; 57: 584-8$

18. Alto-Setala, K, Palomaki H, Miettinen H, Vuorio A, Kuusi T, Raininko R, et al. Genetic risk factors and ischemic cerebrovascular disease: Role of common variation of the genes encoding apolipoproteins and angiotensin-converting enzyme. Ann Med 1998;30:224-33.

Accepted on 08-10-2009

Source of Support: Nil, Conflict of Interest: None declared. 